Georgetown University Law Center

Scholarship @ GEORGETOWN LAW

2020

\title{
(Not the) Same Old Story: Invisible Reasons for Rejecting Invisible Wounds
}

Jessica Lynn Wherry

Georgetown University Law Center / George Washington University Law Center, jlc287@law.georgetown.edu

This paper can be downloaded free of charge from:

https://scholarship.law.georgetown.edu/facpub/2322

https://ssrn.com/abstract=3648636

Legal Communication \& Rhetoric: JALWD, Vol. 17, Fall 2020, Pp. 15-37.

This open-access article is brought to you by the Georgetown Law Library. Posted with permission of the author. Follow this and additional works at: https://scholarship.law.georgetown.edu/facpub

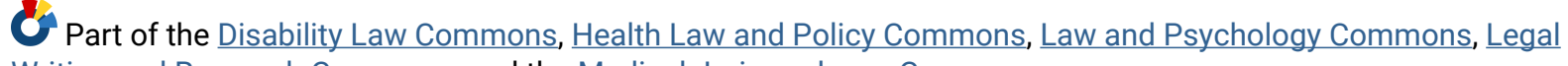
Writing and Research Commons, and the Medical Jurisprudence Commons 


\title{
(Not the) Same Old Story Invisible Reasons for Rejecting Invisible Wounds
}

\author{
Jessica Lynn Wherry*
}

Thousands of former military servicemembers have been discharged with other-than-honorable discharges due to misconduct that can be traced to a mental health condition. In May 2017, the Government Accountability Office reported that sixty-two percent of the 91,764 servicemembers discharged "for misconduct from fiscal years 2011 through $2015 \ldots$ had been diagnosed within the 2 years prior to separation with [post-traumatic stress disorder], [traumatic brain injury], or certain other conditions that could be associated with misconduct."' In that five-year period, 57,141 servicemembers were discharged from the military for what may have been behavior that resulted from a mental health condition rather than willful misconduct. ${ }^{2}$

With an other-than-honorable discharge, veterans are "generally ineligible to receive VA benefits, including education, housing, employment, disability compensation, burial benefits, and in many cases, even healthcare." ${ }^{3}$ They may also be banned from joining veterans' service

\footnotetext{
* Professor of Law, Legal Practice, Georgetown Law. J.D., The George Washington University Law School; M.S.Sc., Syracuse University Maxwell School of Public Affairs; B.A., Lawrence University; Certificate in Military \& Veterans Health, Policy \& Advocacy, Lewis B. Puller, Jr. Veterans Benefits Clinic, William \& Mary Law School. Thank you to Ruth Anne Robbins for encouraging me to write this article and for thoughtful comments on an idea-stage draft. Thank you to journal editors Kristen Murray and Aliza Milner for their insightful suggestions and guidance throughout the editing process.
}

1 U.S. Gov't Accountability Office, GAO-17-260, DOD Health: Actions Needed to Ensure Post-Traumatic Stress Disorder and Traumatic Brain Injury Are Considered in Misconduct Separations 12 (2017), https:// www.gao.gov/assets/690/684608.pdf.

2 Id.

3 Sundiata Sidibe \& Francisco Unger, Unfinished Business: Correcting "Bad Paper" for Veterans with PTSD 3 (2016), https://www.vetsprobono.org/library/item.655356-Unfinished_Business_Correcting_Bad_Paper_for_Veterans_ with_PTSD; see also Stacey-Rae Simcox, Thirty Years of Veterans Law: Welcome to the Wild West, 67 KanSas L. Rev. 513, 564 (2019); Marcy L. Karin, “Other Than Honorable” Discrimination, 67 CASE W. Res. L. Rev. 135, 137-39 (2016) (discussing how the Uniformed Services Employment and Reemployment Act (USERRA) has not protected veterans with other than honorable discharge and explaining that these discharges "have disproportionately impacted people with service-connected injuries like post-traumatic stress disorder and traumatic brain injury, servicemembers who have experienced military sexual trauma, and people with caregiving responsibilities"); U.S. Dep't of Defense InStruction 1300.15, Military Funeral Support 3-4 (Dec. 27, 2017), https://www.esd.whs.mil/Portals/54/Documents/DD/issuances/dodi/130015p.pdf. 
organizations, face challenges in employment, and experience homelessness. ${ }^{4}$ These veterans are also "more likely to suffer mental health conditions ... and to be involved with the criminal justice system, and they take their lives twice as often as other veterans." ${ }^{5}$ Beyond health care and economic resources, veterans with other-than-honorable discharges suffer a diminished status. They are "not permitted to wear their uniforms or receive a military burial." ${ }^{6}$ In sum, their service is not honored and an other-than-honorable discharge "impos[es] a lifetime stigma that marks the former service members as having failed family, friends, and country."

These veterans kicked out of the military with an other-thanhonorable discharge may request a post-discharge change to their discharge characterization-known as a "discharge upgrade." Veterans who seek an upgrade in the fifteen years following discharge can do so through a uniform process, typically proceeding pro se, by submitting a standardized form to a discharge review board. ${ }^{8}$ There are two grounds for granting an upgrade: equity and impropriety. ${ }^{9}$ Generally, equity is a question of fairness and consistency. ${ }^{10}$ Equity considers how policy or procedural changes cast doubt on the fairness of the original discharge decision, and it creates space to provide relief based on a holistic view of an applicant's quality of service and capability to serve. ${ }^{11}$ Impropriety is a matter of prejudice to the veteran due to "an error of fact, law, procedure, or discretion."12 The

4 Sidibe \& Unger, supra note 3, at 3. "Bad paper" means "other-than-honorable, bad conduct, or dishonorable discharge, and may include a general discharge as well." Michael J. Wishnie, "A Boy Gets Into Trouble": Service Members, Civil Rights, and Veterans' Law Exceptionalism, 97 B.U. L. Rev. 1709, 1724 (2017).

5 Wishnie, supra note 4, at 1724; see also Human Rights Watch, Booted: Lack of Recourse for Wrongfully Discharged US Military Rape Survivors 4-5 (2016), https://www.hrw.org/report/2016/05/19/booted/lack-recoursewrongfully-discharged-us-military-rape-survivors. Note that I am not saying discharge status caused these effects, but there is a correlation. See, e.g., id. at 77 ("A strong correlation exists between PTSD, substance abuse, and persistent misconduct." (citations omitted)).

6 Human Rights Watch, supra note 5, at 5; 38 U.S.C. $\$ 2302$ (2018); 38 U.S.C. $\$ 101(2)$ (2018) (limiting benefit to "veteran" defined as "person who served in the active military, naval, or air service, and who was discharged or released therefrom under conditions other than dishonorable"); Eligibility for Burial in a VA National Cemetery, U.S. Dep'T Of Veterans AfFAIRs, https://www.va.gov/burials-memorials/eligibility/ (last visited Apr. 15, 2020).

7 Wishnie, supra note 4 , at 1725.

8 Military records correction boards accept discharge upgrade requests for veterans seeking an upgrade more than fifteen years since discharge. The records correction boards also take appeals of discharge review board decisions. This article focuses on discharge review board decisions because they are the first level of review and because a significant population of veterans discharged for behavior that may have been misconduct were discharged within the last fifteen years. 10 U.S.C. $\$$ 1553(a) (2018); see also Army Discharge Review Board FAQ, Army Review Bds. Agency, https://arba.army.pentagon.mil/ adrb-faq.html (last visited Apr. 15, 2020) ("[Y]ou may appeal the written discharge review decision by applying to the Army Board for Correction of Military Records (ABCMR).").

932 C.F.R. $\$ 70.9$ (a) (2020).

1032 C.F.R. $\$ 70.9$ (c).

$11 \mathrm{Id}$.

1232 C.F.R. $\$ 70.9$ (b)(1)(i). 
board then considers the request, typically based on the paper file only, and almost always denies the upgrade request. ${ }^{13}$

In the past few years, the Department of Defense (DoD) has become increasingly aware of mental health conditions related to post-traumatic stress disorder (PTSD), traumatic brain injury (TBI), sexual assault, and sexual harassment. There is a significant amount of research and scholarship on the connections between PTSD and behavior, including how PTSD symptoms can manifest in a way that looks like misconduct. ${ }^{14}$ In 2014, recognizing the connections between mental health and misconduct and how those connections require a change in the way misconduct is viewed in discharge upgrade decisions, DoD issued policy guidance to the administrative boards charged with reviewing discharge upgrade applications. ${ }^{15}$

The policy guidance requires the boards to give "liberal consideration" to "veterans petitioning for discharge relief when the application for relief is based in whole or in part on matters relating to mental health conditions, including PTSD; TBI; sexual assault; or sexual harassment."16 The policy guidance did not change the standard for granting an upgrade-the grounds are still inequity or impropriety. Instead, within the equity standard, liberal consideration shines a light on mental health conditions as "[i]nvisible wounds," and requires boards to "consider the unique nature of these cases and afford each veteran a reasonable opportunity for relief even if the sexual assault or sexual harassment was unreported, or the mental health condition was not diagnosed until years later."17 Indeed, liberal consideration mandates a relaxed view of misconduct as mitigated by a mental health condition. Liberal consideration also requires a change in how facts are interpreted under the standard: behavior that was understood as misconduct may actually be

13 As many as ninety to ninety-nine percent of applications are denied. HumAn Rights WATCH, supra note 5, at 5 ("Despite the high stakes for veterans, there is little meaningful opportunity to appeal a bad discharge (also called applying for an 'upgrade')."). Decisions take up to a year or more. Check Status/Result of You[r] Application, Council of Review Bds., https://www.secnav.navy.mil/mra/CORB/Pages/NDRB/csra.aspx (last visited Apr. 15, 2020); see also Robert Powers, President, Naval Discharge Review Bd., Sec'y of the Navy, Council of Review Bds., NDRB Presentation to Veterans Legal Assistance Conference of 2019, at slide 4 (June 7, 2019) (slides on file with author) (showing an average length of ten months to decision for documentary review and twenty-two months to decision for personal appearance hearing).

14 See, e.g., What is Posttraumatic Stress Disorder?, Am. Psychiatric Ass'N, https://www.psychiatry.org/patients-families/ ptsd/what-is-ptsd (last visited Apr. 15, 2020); PTSD Basics, NAT'L CTR. FOR PTSD, https://www.ptsd.va.gov/understand/ what/ptsd_basics.asp (last visited Apr. 15, 2020); NAT'L Ctr. For PTSD, IraQ WAR Clinician Guide, 58-60 (2d ed. 2004), https://www.phoenixhouse.org/wp-content/uploads/2010/12/iraq_clinician_guide_v2.pdf.

15 See Memorandum from Chuck Hagel, Sec'y of Defense, to Secretaries of The Military Departments (Sept. 3, 2014), https://www.secnav.navy.mil/mra/bcnr/Documents/HagelMemo.pdf [hereinafter Hagel Memo].

16 See Memorandum from A.M. Kurta, Acting Under Sec'y of Defense for Personnel and Readiness, to Secretaries of The Military Departments, Attach. 3 (Aug. 25, 2017), https://dod.defense.gov/Portals/1/Documents/pubs/ClarifyingGuidance-to-Military-Discharge-Review-Boards.pdf [hereinafter Kurta Memo] (supplementing the Hagel Memo).

17 Id. at Memorandum. 
behavior consistent with a mental health condition, and equity demands relief in those circumstances.

When this policy was announced in 2014 and supplemented in 2017 to provide more detailed implementation guidance, veterans advocates were optimistic about what liberal consideration would mean for veterans discharged with an other-than-honorable discharge. ${ }^{18}$ However, despite some initial increases in upgrade rates, over time, the policy has not been implemented as expected. Recent reports from the boards suggest that liberal consideration has not provided the intended relief as the typically low rate of upgrades continues. ${ }^{19}$ Consistent with these reports, there are two pending class actions against the Army ${ }^{20}$ and $\mathrm{Navy}^{21}$ for failure to implement liberal consideration. Federal district courts certified a class in both lawsuits, recognizing the boards' failure to fully implement liberal consideration. ${ }^{22}$ The court in each case also denied the motions to dismiss, and the cases are now pending with judicial settlement conferences set for $2020 .{ }^{23}$

This article seeks to explore why liberal consideration has not had its intended effect. Rather than take on a comprehensive evaluation of the liberal consideration policy, ${ }^{24}$ the article looks to storytelling and rhetorical principles to consider a possible explanation for the boards' failure to embrace liberal consideration. The article applies a narrow slice of storytelling scholarship-how humans respond to stories-to the specific context of discharge review board decisions.

The growing body of scholarship about storytelling and legal practice is rooted in the traditional context of the adversarial legal system, ${ }^{25}$ but this article proposes a broader applicability. In the traditional context,

18 See Nikki Wentling, Pentagon Expands Policy to Upgrade Vets' Bad Paper Discharges, Stars \& Stripes, Aug. 29, 2017, https://www.stripes.com/news/pentagon-expands-policy-to-upgrade-vets-bad-paper-discharges-1.485038.

19 Powers, supra note 13 , at slide 3.

20 Kennedy v. Esper, No. 16cv2010 (WWE), 2019 WL 7290933, slip op. (D. Conn. Jan. 9, 2019); see also Kennedy v. Esper, YALE L. SCH., https://law.yale.edu/studying-law-yale/clinical-and-experiential-learning/our-clinics/veterans-legal-servicesclinic/kennedy-v-esper (last visited June 14, 2020).

21 Manker v. Spencer, No. 3:18-cv-00372 (CSH), 2019 WL 5846828, slip op. (D. Conn. Nov. 7, 2019); see also Manker v. Spencer, YALE L. SCH., https://law.yale.edu/studying-law-yale/clinical-and-experiential-learning/our-clinics/veterans-legalservices-clinic/manker-v-spencer (last visited June 14, 2020).

22 In Kennedy v. Esper, the case against the Army, the court certified a class of Army veterans of the Iraq and Afghanistan era. Kennedy v. Esper, No. 16cv2010 (WWE), 2018 WL 6727353 (D. Conn. Dec. 21, 2018). In Manker v. Spencer, the case against the Navy, the court certified a class of Navy and Marine Corps veterans of the Iraq and Afghanistan era. Manker v. Spencer, 329 F.R.D. 110 (D. Conn. 2018).

23 Kennedy, 2019 WL 7290933, at "2; Manker, 2019 WL 5846828, at *20; Posting of Michael Wishnie, michael.wishnie@yale. edu, to veteransclinics@lists.wm.edu (Nov.30, 2019 6:11 PM) (on file with author).

24 I discuss the liberal consideration policy in more depth in Jessica Lynn Wherry, Kicked Out, Kicked Again: The Discharge Review Boards' Illiberal Application of Liberal Consideration for Veterans with Post-Traumatic Stress Disorder, 108 CALIF. L. REv. __ (forthcoming 2020). That article (and this article) grew out of my experience in the Navy, my pro bono work for veterans, and my longstanding respect for all who serve in the military.

25 See Ruth Anne Robbins, An Introduction to Applied Legal Storytelling and to This Symposium, 14 Legal Writing 3, 3 (2008) ("Storytelling is the backbone of the all-important theory of the case, which is the essence of all client-centered lawyering."). 
lawyers are the storytellers telling their clients' stories. The judges are the story-receivers and they make decisions based on their evaluation of those stories. The client, of course, also plays a role, but an indirect one, through an advocate's decisions about how to best present a client's case.

In this article, I redefine those traditional roles in the context of the discharge upgrade system where most applicants are pro se, board members are not judges, and decisions are almost always limited to the paper file. Specifically, I see the DoD Policy Memo ${ }^{26}$ standing in as the advocate and liberal consideration as the story the advocate tells. The Memo stands in as advocate for the typically pro se veteran-applicants by recognizing mental health conditions and their relationship to behavior, and laying out how to apply liberal consideration to support an upgrade. ${ }^{27}$ In tandem with the specific facts the veteran-applicant includes in the request, liberal consideration is the story that overlays any application invoking a mental health condition as a mitigating circumstance. In their role as story-receiver, board members are like judges in legal storytelling literature even though board members are not legally trained. In their judge-like role, board members evaluate stories as part of their decisionmaking in applying standards to facts. Given the policy mandate to give liberal consideration to cases involving mental health conditions, board members also have a significant role in bringing the story into the decisionmaking process.

Humans, including board members, respond to stories in three ways: response-shaping, response-reinforcing, and response-changing. ${ }^{28}$ Stories that teach something new are response-shaping. ${ }^{29}$ Stories that reflect the audience's existing knowledge are response-reinforcing. ${ }^{30}$ And stories that try to break patterns of existing knowledge or beliefs are responsechanging. ${ }^{31}$ Our responses to stories are heavily influenced by our past experiences with similar, or what appear to be similar, stories. The more we think a certain way about, or categorize, a certain fact or set of facts, the more our brain becomes embedded with that particular thought pattern and the more closed off it becomes to alternative stories and especially to a story that demands a response-change.

26 I use the general term "DoD Policy Memo" to mean the liberal consideration policy as a whole, including the original Hagel Memo and the Kurta Memo's supplemental guidance. See Hagel Memo, supra note 15; Kurta Memo, supra note 16.

27 Of course, the pro se applicant may also be telling a story, and some may be able to tell a coherent story, but the DoD Policy Memo stands in on behalf of the veteran no matter the substantive quality of the application. Advocates, too, can use the principles of liberal consideration in representing their veteran clients.

28 Robbins, supra note 25 , at 6-7.

$29 \mathrm{Id}$. at 7. 
This article explores how liberal consideration as a policy could be thwarted by board members' preference for response-reinforcement and a resistance to response-change in the form of invisible rigid categories and neural pathways. There are probably a number of reasons why boards are failing to properly or fully implement liberal consideration, ${ }^{32}$ but what if one of the reasons-or even the primary reason-is invisible? What if board members are not able to receive and process liberal consideration as a new story? What if board members are not aware of their resistance to the new story?

In exploring answers to these questions, this article does not attempt to engage with the full body of storytelling scholarship. Rather, it draws on response-reinforcement and related rhetorical principles of categories and neural pathways to explore one possible explanation for why the discharge review boards have not fully implemented liberal consideration. The article engages with Professors Lucy Jewel's and Linda Berger's work about how judges and all humans think in terms of categories and neural pathways to explore board members' decisionmaking as an example of response-reinforcement. Building on the ways humans respond to stories, section I briefly summarizes two relevant rhetorical principles, rigid categories and neural pathways, in the context of response-reinforcement. Section II further explains liberal consideration as a new story. In section III, the article applies the principles of rigid categories and neural pathways to offer one possible explanation for the boards' failure to fully implement liberal consideration. The article concludes with suggestions for going forward.

\section{Response-Reinforcement Roots: Categories and Neural Pathways}

As humans, we like stories to be consistent with stories we have heard before, and our brains are trained to reinforce what we already know-or think we know. This preference for response-reinforcement can be further understood by considering Professor Jewel's analysis about how harmful rhetoric creates toxic neural pathways in relation to racial minorities and other subordinated groups in ways that reinforce stereotypes. ${ }^{33}$ Neurorhetoric, "the study of how rhetoric shapes the human brain," uses

32 For example, bias may be at play here. Or it may be that the requests for upgrade do not merit relief even within the liberal consideration construct. This article is not trying to determine the possible multiple reasons for liberal consideration's failure to increase the rate of discharge upgrades, but rather considers just one possibility by taking a narrow look through the lens of storytelling to suggest what may be underneath the boards' lack of implementation.

33 See generally Lucy Jewel, Neurorhetoric, Race, and the Law: Toxic Neural Pathways and Healing Alternatives, 76 MD. L. REv. 663 (2017). 
"neuroscience to understand how rhetoric stimulates activity that can actually change the shape and form of the brain." ${ }^{44}$ The brain is shaped by words and phrases or ideas that "become cemented in the brain." ${ }^{35}$ Once cemented, those words and phrases or ideas influence responses to stories by cutting off alternatives that are in conflict with the cemented ideas. ${ }^{36} \mathrm{In}$ this brief background section, I focus on two interrelated concepts: categories and entrenched neural pathways. ${ }^{37}$

First, categories are a way to make sense of information in an efficient way. How we categorize information is relatively complex, and the actual categories are "often based on subjective choices that are products of one's culture and individual experiences." ${ }^{38}$ Categories can be constraining because they limit thinking to a "common stock of ideas," when there may be other ideas beyond those categories. ${ }^{39}$ Categories can change or arise in response to changes in the world. But categories can also blind the brain to any alternatives. This blindness is particularly problematic when categories cause unconscious - invisible - thinking and decisionmaking. If used "rigidly and uncritically, [categories] generate less-robust legal reasoning and may also become a tool for reproducing injustice in the law." ${ }^{40}$ For example, in discussing racially coded categories' collective entrenchment, Professor Jewel explains that

[c] oded categories are harmful because they encourage rapid unconscious thinking that has the effect of hardwiring stereotypes into the pathways of the brain. The rapid way in which a term raises these unspoken conclusions makes it difficult to imagine other narrative possibilities or engage in reasoned deliberation about the issue. ${ }^{41}$

Thus, the power of categories in humans' responses to stories may thwart response-change even when a change is warranted.

Second, the more our brains think a certain way, the more entrenched that thinking becomes. This entrenched thinking creates neural pathways in the brain, and these pathways are reinforced by repeated thinking in

$34 \mathrm{Id}$. at 663,665 .

35 Id. at 671.

$36 \mathrm{Id}$.

37 This article does not even scratch the surface as far as explaining these and other principles of neurorhetoric, and instead merely lays out a brief foundation for its later suggestions for why liberal consideration has not been fully implemented.

38 Lucille A. Jewel, Old-School Rhetoric and New-School Cognitive Science: The Enduring Power of Logocentric Categories, 13 Legal Comm. \& Rhetoric 39, 45 (2016).

39 Id. at 51 .

$40 \mathrm{Id}$.

41 Jewel, supra note 33, at 664 . 
response to certain similar information. The idea that "some or a few attributes of a category stand for the whole" leads to stereotyping and an inability to see alternatives, while also sustaining a level of efficiency. ${ }^{42}$ As "neuroscientific theory" explains, "the more a particular thought pattern is repeated, the deeper it gets into our brains. Thus, the repeated use of specific language forms creates collective neural pathways that become collectively entrenched." 43

Through canalization and attenuation, entrenched thinking becomes further entrenched as ideas become cemented in the brain. Canalization is like the tracks created by repeatedly sledding over the same path. ${ }^{44}$ The path becomes deeper, faster, and more efficient at keeping the sled on the track with nothing in its way. The more a brain experiences the same thought in response to certain facts, the deeper and faster that thought becomes in response to similar facts. ${ }^{45}$ Attenuation can cut off alternative pathways because the brain has a limited capacity and the neural pathways compete in a way that "the connections that are used are kept and those that go unused are eliminated." 46 Thus, the more entrenched our ideas, "the more certainty we have with respect to the associated thought," and the harder it is to break that thought pattern and be open to alternatives. ${ }^{47}$

Neurorhetoric also suggests that there is a physical connection to thought. A "'gut feeling" is an example of "the embodied nature of thought." ${ }^{48}$ This physical connection is recognized in the term "somatic marker." ${ }^{99}$ As Prof. Jewel explains, Neuroscientist Antonio Damasio's term somatic marker is rooted in "soma coming from the Greek word for body and marker reflecting the impact that previous thought experiences have had on our brains." ${ }^{50}$ Just as entrenched neural pathways influence our thinking, "[s]omatic markers represent canalized thought patterns that guide the direction, rapidly and unconsciously, of our thought processes."51

42 Id. at $667-68$.

$43 \mathrm{Id}$. at 681 . This collective entrenchment is seen in how judges "draw on embedded knowledge structures, and they tend to turn first to whatever 'commonsense background theory [is] prevalent in the legal culture of their era." Linda L. Berger, How Embedded Knowledge Structures Affect Judicial Decision Making: A Rhetorical Analysis of Metaphor, Narrative, and Imagination in Child Custody Disputes, 18 S. CAL. InTERDISC. L.J. 259, 284 (2009).

44 Jewel, supra note 33 , at 670 .

$45 \mathrm{Id}$.

46 Id. at 671.

47 Id. Repetitive thinking that "continu[ally] activat[es] . . the same neural pathways by the same stimulus," is "highly difficult to undo." Id.

$48 I d$. at 672.

$49 \mathrm{Id}$.

50 Id. 
Our brains are marked by these repeated thoughts, and those somatic markers "function as a 'biasing device," further cutting off alternative responses to information that appears similar to past information. ${ }^{52}$ Thus, "rhetoric can get inside our brains and bodies and make us think and feel things without the intervention of conscious rationality." ${ }_{33}$

Categories and entrenched neural pathways are consistent with response-reinforcement as a reaction to a story. The brain likes what it already thinks and knows, or what it thinks it knows. Faced with new information, the brain will try to place that information within existing categories and neural pathways rather than develop a new category or pathway. At the same time, this preference for response-reinforcement continues to guard against new ideas and new stories. In applying these concepts to discharge upgrades, the article next explains liberal consideration as a new story. It then applies these rhetorical concepts to explore why liberal consideration has not spurred board members to responsechange in their consideration of discharge upgrade requests.

\section{Liberal Consideration: A New Story}

As I articulated in the introduction to this article, my view of the DoD Policy Memo as storyteller and liberal consideration as story is different from the traditional paradigm of lawyer as storyteller and client's case as story framed favorably. Given the distinct features of the discharge upgrade process, there is very little opportunity for traditional storytelling. For example, the brevity of the form limits storytelling by asking a series of questions with check boxes and small fields for very brief open narrative. Furthermore, the typical pro se veteran-applicant likely does not know how to supplement the form with a persuasive narrative. Given the prevalence of pro se applicants, the DoD Policy Memo stands in as an advocate for the veteran-applicant and tells the liberal consideration story about how the veteran's mental health condition mitigates misconduct to justify an upgrade. In this article, I am taking an outside look in to try to understand a possible reason the liberal consideration story is not having its intended effect.

Liberal consideration is a distinct departure from the historic view of misconduct as willful behavior deserving punishment. Liberal consideration does not change the standard for granting an upgrade-that remains inequity or impropriety. But it does change-or intends to 
change-the lens through which board members evaluate a veteran's request for upgrade in the specific context of mental health conditions and their effects on behavior.

Liberal consideration tells a new story about how to understand misconduct. When a veteran's upgrade request identifies a mental health condition as a basis for relief, liberal consideration explains the connection between mental health conditions and behavior, weaving together a story based on the veteran's facts and the research supporting the connections between mental health conditions and behavior. The liberal consideration story explicitly recognizes that there are mental health conditions and experiences that excuse, explain, or mitigate what seems to be bad behavior (and what has been historically viewed as bad behavior). ${ }^{54}$ Under the principles of liberal consideration as a policy, the board members must consider "changes in behavior; ... deterioration in work performance; inability of the individual to conform their behavior to the expectations of a military environment; [and] substance abuse" in evaluating whether a veteran suffered from a mental health condition that produced behavior misidentified as misconduct. ${ }^{55}$

For this unique administrative body, board members have a responsibility as decisionmakers to evaluate the facts in light of liberal consideration, to receive the liberal consideration story and apply it to the veteran's facts. Unlike a situation where the law changes and an advocate then adapts her strategy, here, the law has not changed, but rather how to perceive facts under the law has changed. Board members are uniquely positioned as the (often) sole implementers of that change in perception. Through liberal consideration, the DoD Policy Memo as storyteller is trying to dislodge board members' strict view of misconduct as willful acts and induce them to see that same misconduct as part of a different story in light of the research demonstrating a connection between mental health conditions and behavior. Moreover, the DoD Policy Memo mandates that board members consider liberal consideration even if the veteran-applicant does not explicitly mention it, as long as the veteran asserts a mental health condition as a basis for relief.

Liberal consideration as story presents the opportunity for responsechanging, by creating "new knowledge" about how to interpret facts within the equity standard. This new knowledge is the explicit recognition of and explanation for the relationship between mental health conditions and misconduct, and how that relationship mitigates misconduct to justify an upgrade. Liberal consideration is a new story: a veteran's misconduct 
was actually the result of a mental health condition and the veteran deserves relief. And yet, the boards continue to regularly deny upgrade requests, reflecting the "historic hostility' in the military toward veterans with other-than-honorable discharges." 56 This resistance to upgrades reflects board members' response-reinforcing approach and further entrenches the boards' historical resistance to granting relief by closing off alternative views of the facts.

\section{Response-Reinforcement: Invisible Reasons for Rejecting Invisible Wounds}

The board members' response-reinforcing approach continues despite the DoD Policy Memo requiring a different interpretation of what seems to be, but is not, the same old story. Given the military's unique goodorder-and-discipline-based culture and war-driven existence, ${ }^{57}$ categories and entrenched neural pathways may be at play in the board members' decisionmaking. The uniquely military rhetoric used to maintain order and discipline likely creates deeply embedded and, ultimately, toxic neural pathways in the specific context of mental health in the military. With the deeply-rooted idea of a soldier or sailor as one who is strong and supports the mission over self, failure to do so is seen as failure, as weakness. When there is a physical injury that occurs as a result of military service, the servicemember may be honored even though the servicemember is physically unable to continue to fight. However, when there is a mental injury-an invisible wound-that occurs as a result of military service, the servicemember may be categorized as weak, failing to meet her duty, or otherwise unworthy of honor. That category is reflected at the time of discharge with an other-than-honorable discharge characterization, and then again when the discharge review boards regularly affirm the original decision rather than grant relief.

Consistent with the class action lawsuits against the Army and the Navy that allege the boards' failure to fully implement liberal consideration, Naval Discharge Review Board (NDRB) decisions from 2017-2019 include a number of examples that illustrate how response-reinforcement may be thwarting liberal consideration. ${ }^{58}$ Those decisions suggest a deeply-

56 Wentling, supra note 18 (quoting Professor Michael Wishnie).

57 See Jeremy S. Weber, Whatever Happened to Military Good Order and Discipline?, 66 Clev. St. L. Rev. 123, 128-29 (2017) (discussing the military's "need to maintain good order and discipline" and "primary goal" to win wars).

58 As a practical matter, the NDRB decisions are used here because they are the decisions I had access to even after the Department of Defense online reading room that formerly provided access to all the boards' decisions was shut down for an indeterminable amount of time. I started my research in January 2019 with the NDRB decisions and fortunately downloaded about 500 decisions before the reading room disappeared. Relatedly, I focused on the NDRB decisions because I am a veteran of the United States Navy. 
embedded skepticism and rejection of the idea that a mental health condition can be a legitimate explanation for a failure to follow the rules. Veterans are repeatedly denied relief even with evidence of a diagnosed mental health condition. This disbelief and rejection continue despite the policy mandate to give liberal consideration to cases involving mental health conditions; liberal consideration is a policy intended to offer all veterans with invisible wounds "a reasonable opportunity for relief" and to require the boards to give consideration to the "unique nature of these cases." 59 Two potential invisible reasons for the boards' continued rejection of invisible wounds center on the neurorhetoric concepts discussed above: categories and neural pathways.

\section{A. Rigid Categories Rooted in Military Culture}

Board members are typically mid-ranking career military officers. ${ }^{60}$ Though they are not judges and are not legally trained, board members are tasked with applying standards to facts to reach a decision. In making these discharge upgrade decisions, board members likely do the same as judges: "draw on embedded knowledge structures, and they tend to turn first to whatever 'commonsense background theory [is] prevalent in the legal culture of their era." ${ }^{61}$ Instead of "legal culture," we can think of board members as looking for commonsense theories prevalent within their military culture. For example, one commonsense theory may be disciplinarian in the context of the "need to maintain good order and discipline," and board members may operate consistent with commanders' "central disciplinarian role." ${ }^{2}$ In addition, culture and individual experiences may be particularly influential on categories within the military given the deeply-rooted culture of giving and following orders.

Categories help humans streamline information, as part of cognitive rhetoric that helps explain how human minds respond to stimuli, or facts. Just as a warm and caring person may be categorized as motherly or maternal, ${ }^{63}$ military personnel may be categorized as strong and committed to mission over self. The alternative to being strong and mission-focused is being weak and unable to contribute to the mission.

59 Kurta Memo, supra note 16.

60 Sec'y of the Navy: Naval Discharge Review Board (NDRB) Procedures and Standards, SeCnavinst 5420.174D 403.A.(2)-(3) (Dec. 22, 2004), https://www.secnav.navy.mil/doni/Directives/05000\%20General\%20 Management\%20Security\%20and\%20Safety\%20Services/05-400\%20Organization\%20and\%20Functional\%20Support\%20 Services/5420.174D.pdf.

61 Berger, supra note 43, at 284.

62 See Weber, supra note 57, at 129.

63 Jewel, supra note 33, at 667; Berger, supra note 43, at 277. 
The physical nature of being in the military contributes to these categories because physical strength is an inherent part of military service. Sailors, for example, learn the Navy's core values ${ }^{64}$ during recruit training-boot camp-where group physical activity is the focus. Sailors learn to function as a group; if one sailor fails to meet a goal, the entire group of recruits fails and has to start over. The bodily experience of boot camp and regular physical training requirements permanently embed the idea of strength and prioritizing mission over self within the military "category," which also includes the ability to conform to military requirements. Put another way in military cultural terms, based on these characteristics, one is categorized as either fit or unfit for service.

The board members' failure to implement liberal considerationa policy intended to recognize the relationship between misconduct and mental health conditions-may be in part explained by the power of categorization, specifically that of fit vs. unfit. When there is some misconduct-a violation of the Uniform Code of Military Justice (UCMJ) - that misconduct is almost invariably treated as a basis for unfitness rather than recognized as behavior consistent with a mental health condition. Instead of recognizing the complexity of each individual veteran's experience, including the specific stressor that gave rise to PTSD, how a veteran coped with PTSD, and how any behavior that looks like misconduct could actually be consistent with PTSD, board members seem to revert to a simpler category: fit or unfit. ${ }^{65}$ Thus, the board members may assume that "some or a few attributes of a category stand for the whole" 66 when the attribute is misconduct standing for unfit as the whole, making the veteran undeserving of an upgrade.

Before PTSD was recognized as a mental health condition, servicemembers or veterans who claimed they experienced PTSD were categorized as weak, dishonorable, and unfit for further service. Consistent with the mind's desire to "simplify complex information," ${ }^{67}$ rather than try to understand the complex mental health effects of combat or other aspects of military service, the military's standard response has been to blame the individual for failing to meet mission and justify discharge due to the person's unfitness for service. Even now, with PTSD as a recognized mental health condition and decades of research to explain what PTSD is and how it affects behavior, the complexity remains. That complexity

64 The Navy's core values are Honor, Courage, and Commitment. Dep't of the Navy Core Values Charter, SEC'Y OF THE NAvy Ethics, https://www.secnav.navy.mil/Ethics/Pages/corevaluescharter.aspx (last visited Apr. 15, 2020).

65 See Jewel, supra note 33, at 672 (discussing the connection between physical experience and thought).

$66 \mathrm{Id}$. at 668 .

67 Id. at 667. 
is easily resolved by reverting to well-known categories of fit and unfit, placing those with PTSD in the unfit category. ${ }^{68}$

In over 100 of approximately 500 decisions involving mental health conditions released between August 2017 and January 2019, the Board relied on the category of unfit in concluding that "the record reflects willful misconduct that demonstrated [the veteran] was unfit for further service." ${ }^{69}$ The category of unfit was commonly used to reject veterans' claims that PTSD or other mental health condition mitigated behavior as a justification for an upgrade. The decisions have very little, and often no, explanation for how or why PTSD or other mental health condition did not mitigate misconduct, but rather just repeat the long-used phrase. ${ }^{70}$ This lack of explanation suggests the power of the categories and the deeply-rooted connection between misconduct and unfitness for duty; the categories block the board members from receiving the liberal consideration story.

"Drug use" is another term or specific type of misconduct that particularly illustrates how categories prevent implementation of liberal consideration. Drug use is a violation of the UCMJ and, for the Navy, means automatic separation from service. ${ }^{71}$ But this automatic separation and zero tolerance view of drug use is at odds with liberal consideration. Liberal consideration recognizes that a mental health condition can mitigate what otherwise may appear to be willful misconduct. Liberal consideration explicitly discusses drug use as a coping mechanism for PTSD, and in doing so, identifies a specific alternative narrative. ${ }^{72}$ Rather than viewing drug use exclusively as willful misconduct, liberal consideration recognizes that drug use may be a symptom of a mental health condition incurred while in service, and therefore a basis for upgrade. This alternative narrative does not appear in the Board's decisions.

For example, in a case involving drug use, the veteran offered evidence of a sexual assault report, mental health conditions, and a post-service

68 Simcox, supra note 3, at 562 ("Oftentimes, the behavior associated with PTSD and TBI is behavior that puts servicemembers directly at odds with their commanders and the larger military culture."). Some of the "symptoms associated with PTSD and TBI, such as poor impulse control, loss of temper, impaired thinking, and poor exercise of judgment, may appear indistinguishable from the behavior of a servicemember who has chosen to rebel against the good order and discipline so necessary to the military's culture." Id.

69 E.g., ND17-01088, at 3 (2018) (on file with author).

70 See Jewel, supra note 38, at 51. ("[W]hen categories are used rigidly and uncritically, they generate less-robust legal reasoning and may also become a tool for reproducing injustice in the law.").

7110 U.S.C. $\$ 912 \mathrm{a}$ (2018) (subjecting wrongful use, possession, manufacture, or distribution of controlled substances to punishment "as a court-martial may direct").

72 Kurta Memo, supra note 16, Attach. 5. The Kurta Memo also urges a relaxed view toward drug use as a reflection of many states' legalization of marijuana use, and explains that " $[t]$ he relative severity of some misconduct can change over time, thereby changing the relative weight of the misconduct to the mitigating evidence in a case." Id. Attach. 26.i. 
PTSD diagnosis originating from an in-service military sexual trauma (MST) to justify her request for an upgrade. ${ }^{73}$ The veteran "attribute[d] her drug use to MST brought about after the alleged sexual assault." ${ }^{44}$ Rather than engage with an assessment of whether the MST and other mental health conditions excused or mitigated the drug use, as required by liberal consideration, the board members focused solely on the existence of drug use to reach a negative decision on the basis of drug use as willful misconduct.

Specifically, in this case, the veteran admitted to using drugs prior to enlistment, something she had not admitted to at the time of enlistment. ${ }^{75}$ The board members used that against her in combination with her statement that she used drugs once to self-medicate for food poisoning while on active duty. A former instance of self-medicating-although a willful violation of the UCMJ-has nothing to do with the instance of drug use to cope with PTSD that led to her discharge. The Board's decision, though, suggests that board members used those facts against the veteran in concluding that the mental health condition did not mitigate the drug use. ${ }^{76}$ The decision mentioned mitigation, but did not engage in any sort of balancing to determine or explain why the mental health condition did not mitigate the drug use. ${ }^{77}$ The decision did not even acknowledge that drug use is a recognized coping mechanism for PTSD; that lack of acknowledgement suggests that board members' rigid response to drug use thwarted liberal consideration's alternative, response-changing guidance.

In addition to rigid thinking, categories probably create efficiencies for the board members to quickly decide one upgrade application and move on to the next one in the pile. Relying on willful misconduct as an explanation for a veteran's behavior is an easy way to resolve an application because misconduct typically justifies an other-than-honorable discharge characterization. ${ }^{78}$ But here, the efficiencies are at the cost of full implementation of liberal consideration, a necessarily complicated policy change intended to infuse a better understanding and assessment of mental health conditions and behavior. To the extent categories are used to avoid full implementation of liberal consideration, they blind the

73 ND17-01269, at 3 (2018) (on file with author).

74 Id.

75 Id. at 3-4.

76 Id. at 4.

77 See id.

78 Jewel, supra note 38, at 53 (describing Justice Holmes' overly simple analysis in determining that an airplane is not a vehicle because "vehicle" is commonly understood as "only includ[ing] vehicles running on land"). 
board members from seeing alternatives, even though these alternatives are expressly identified and mandated by the DoD Policy Memo.

\section{B. Entrenched Neural Pathways and Embedded Knowledge Structures: Justification for Denying Relief Despite Liberal Consideration}

When reaching decisions, board members likely draw on embedded knowledge structures, perhaps even more so than judges, because of the well-defined categories of military culture. With the military culture categories as a baseline, embedded knowledge structures are steeped in military ideals such as strength over weakness, and board members may easily justify their decisions by viewing veterans' requests for upgrades as stories about weakness even though liberal consideration explicitly rejects that approach when mental health conditions are involved. Board members' consistent reactions to requests for relief on similar grounds suggest that board members have thoughts "cemented in the brain," and that those thoughts-e.g. zero tolerance for drug use, PTSD does not overcome willful misconduct_-"appear[] with great rapidity and arise[] unconsciously." 79 Indeed, many of the decisions include exact copy and paste text, where the decision gives the same "reason" for rejecting a veteran's upgrade request. Those repeated "reasons" for denying relief demonstrate board members' inability to see the alternatives liberal consideration recognizes and legitimizes, as well as illustrate the power of the brain to repeatedly seek the same neural pathway.

The pattern of using the same language to reject upgrade requests may actually "cut off" alternative responses, including granting an upgrade. The Board's decisions suggest a strong case of attenuation, where the repeated rejection of upgrade requests for certain reasons "continu[ally] activat[es] . . the same neural pathways by the same stimulus," and that repetitive action makes the rejection "highly difficult to undo." ${ }^{80}$ Especially in the military context, where a strict attention to order and discipline overrides everything, these neural pathways block alternatives. The repeated language also demonstrates how "rhetoric can get inside our brains and bodies and make us think and feel things without the intervention of conscious rationality." 81 The nature of the Board's decisions suggests that board members work very much in a repetitive, neural-pathway-creating and entrenching way. Thus, not only is it likely

79 Jewel, supra note 33, at 671.

80 See id.

81 Id. at $671-72$. 
that there is copying and pasting text (from phrases to sentences to full paragraphs) from one decision to another, but board members' brains are repeatedly reinforcing the faulty reasoning used to justify the decisions.

In particular, the NDRB regularly denies relief by concluding that the record does not show that PTSD or another mental health condition was a sufficient mitigating factor to excuse misconduct, often with little explanation for this conclusion. The Board's decisions regularly demonstrate a hard stance against any misconduct and appear to default to treating misconduct as willful rather than recognizing that misconduct can actually be something else: behavior consistent with coping with a mental health condition. For example,

Though the Applicant may feel that MST and other mental health conditions may have been an underlying cause to her misconduct, the record reflects willful misconduct that demonstrated she was unfit for further service. There is not sufficient evidence to suggest that the Applicant's claim of MST or other mental health conditions mitigated the Applicant's misconduct. ${ }^{82}$

This language is repeated or nearly repeated in over 100 decisions between August 2017 and January 2019. This hard stance is an embedded knowledge structure-misconduct should be punished-that impedes the application of liberal consideration.

In contrast, liberal consideration explicitly recognizes that servicemembers experiencing a mental health condition may behave in ways others would not; it recognizes drug use as consistent with coping with PTSD and even calls for a relaxed view of drug use consistent with society's changing view as reflected by decriminalization in many states. ${ }^{83}$ Liberal consideration creates a new story: a servicemember served, experienced a mental health condition due to that service, and then, because of the mental health condition, did something that, although previously treated as misconduct, was actually behavior consistent with a mental health condition. In this new story, the veteran does not deserve to be punished, but rather deserves relief. Yet, board members appear closed off to that alternative view, sticking instead to the historical approach to see misconduct as misconduct, and not as behavior consistent with a mental health condition.

Another example of repeated language highlights the embedded knowledge structure of how seeking assistance means a person has a

82 ND17-01269, at 4. 
mental health condition and not seeking assistance must mean there was no mental health condition.

Additionally, there is insufficient evidence in the record, nor did the Applicant provide any documentation, to indicate she attempted to use the numerous services available for servicemembers who undergo mental health problems, personal problems or are victims of a sexual assault during their enlistment, such as the Navy Chaplain, Medical or Mental Health professionals, Navy Relief Society, Family Advocacy Programs, the Red Cross or a Sexual Assault Victim Advocate/Response Coordinator. Therefore, the NDRB is unable to establish this contention as a basis for mitigation or consideration as an extenuating circumstance. ${ }^{84}$

In 22 decisions (from that same set, August 2017 to January 2019), the Board repeated this "reasoning," concluding that if someone did not seek assistance, they then did not have a mental health condition, because if someone did have a mental health condition, surely, they would seek assistance. Though this language is not repeated as often as other examples, this language illustrates how far board members may go to find ways to reject the alternative story liberal consideration presents and to reinforce the traditional view. Here, the lack of evidence is used against the veteran on no basis other than board members' assumptions that someone who truly needed help would seek help. That assumption is in direct conflict with liberal consideration's principles that a "veteran's testimony alone, oral or written, may establish the existence of a condition or experience" 85 and that "[m]ental health conditions, including PTSD; TBI; sexual assault; and sexual harassment inherently affect one's behaviors and choices causing veterans to think and behave differently than might otherwise be expected." 86

Liberal consideration recognizes that not seeking help may be consistent with a mental health condition, even though there are numerous resources available within the military. Many veterans seeking an upgrade do not have an in-service diagnosis of PTSD or other mental health condition. This makes sense because if a servicemember had an in-service diagnosis, she may have received health care while in service and perhaps never behaved in the ways she did that led to her otherthan-honorable discharge. Liberal consideration makes room for veterans without an in-service diagnosis to be eligible for relief based on a post-

84 ND17-01098, at 3-4 (2018) (on file with author).

85 Kurta Memo, supra note 16, Attach. 7.

86 Id. Attach. 26.e. 
service diagnosis or even on their statement alone when that mental health condition mitigates the misconduct. However, in many cases when there is no in-service diagnosis, board members take the next step to also find no record of the veteran seeking assistance while in the military. Board members then use that lack of seeking help to justify their decision that there was no mental health condition because in the board members' embedded knowledge structure, if a servicemember needed help, they would seek out the help that was available to them. And that story is simple, not requiring board members to try to understand the complexity of someone else's decision not to seek help.

One final example involves a more overt rejection of liberal consideration. In reviewing misconduct and whether a mental health condition mitigated it, the Board decisions often refer to equity and consistency with prior decisions involving similar behavior to justify the lack of mitigation in a current decision. In 144 of the decisions from the NDRB set, the Board used the exact same phrase to sum up its refusal to grant relief:

The NDRB found the characterization of the Applicant's discharge was equitable and consistent with the characterization of discharge given others in similar circumstances. ${ }^{87}$

Though this language appears in some decisions that did not involve mental health conditions, and therefore did not require liberal consideration, the language was used primarily in cases requiring liberal consideration. For those cases involving liberal consideration, this statement represents a contradiction with-or flat-out rejection of-liberal consideration as a new story. Applying the new principles of liberal consideration inherently means that pre-liberal consideration decisions cannot justify post-liberal consideration decisions. Furthermore, in many of these decisions where the Board relies on "precedent," of past decisions, the Board also discusses how the misconduct at issue was isolated. The isolated nature of misconduct is identified by liberal consideration as supportive of relief, recognizing that an upgrade "does not require flawless military service," and that "some relatively minor or infrequent misconduct" is consistent with an Honorable discharge. ${ }^{88}$ Yet board members refuse to see it that way, or simply cannot see it that way because of the ever-deepening neural pathway that rejects the alternatives liberal consideration presents. For board members, it seems that misconduct is misconduct is misconduct. 
These examples represent how board members' invisible thinking (or lack of thinking) may thwart liberal consideration. The typically negative outcomes become "part of [the board members'] collective brain structure," and reaching an alternative outcome requires intentional work to recreate new pathways that will recognize and apply liberal consideration. ${ }^{89}$ Ultimately, neurorhetoric may impede board members from making individualized judgments without even knowing that this effect is happening. In making these judgments, board members are likely guided by somatic markers that "represent canalized thought patterns that guide the direction, rapidly and unconsciously" ${ }^{90}$ Although these somatic markers may create an efficiency in board members' ability to quickly recognize facts they have seen before and make decisions consistent with past decisions on those recognized facts, the efficiency is at the cost of reasoned, individualized decisions with the benefit of the liberal consideration story. Thus, as an entity, the Board has developed and reinforced a bias against granting upgrades, and that bias cannot be overcome simply by a policy change due to board members' canalized thought patterns that did not disappear just because liberal consideration created the space for a new understanding of misconduct.

To some extent, neurorhetoric as an explanation for the failure of liberal consideration is a relief. The policy itself may not be failing, but instead, the problem may be a matter of implementation. Board members need to intentionally shift their thinking in ways that are consistent with liberal consideration's response-changing principles, and veterans and their advocates can help push that shift. Indeed, board members have an obligation to receive-and decide within - the liberal consideration story, even when it is not presented as part of an upgrade request.

\section{Response-Changing: Toward Actual Liberal Consideration}

"[T]he identification and deployment of alternative discourses have the potential to carve out healing pathways that can reshape brains." ${ }^{91}$ DoD has identified alternative discourses by promulgating the liberal consideration policy, but the boards' deployment has fallen short. Board members still need to do the work of suspending disbelief and engaging with the alternative, response-changing liberal consideration story. More 
specifically, board members need to intentionally implant positive pathways by recognizing PTSD and other mental health conditions and their role in mitigating behavior. The more board members engage with liberal consideration to find in favor of granting upgrades, the easier it will become for board members to continue doing so as they break the pattern of denial and intentionally open up to liberal consideration's alternative story.

As Professor Jewel suggests in regard to solving or decreasing toxic racial narratives, there is hope in the young because "their brains have yet to be molded by these longstanding cultural tropes." 92 Perhaps enlisted and officer training programs targeted at junior servicemembers could be developed to educate servicemembers on mental health conditions and how those conditions affect behavior. With that understanding, future board members may be better able to see and accept the specific connection that liberal consideration makes: servicemembers deserve to be recognized, rather than punished, for their service that included suffering from a mental health condition. Even creating a space for discussion about how mental health conditions affect servicemembers' behavior would potentially create room for a new narrative that abandons the traditional narrow and exclusive categories: strong vs. weak, or fit vs. unfit.

For true change, there must be a willingness to listen to and accept alternatives. For example, in the context of racially-coded categories, "mainstream white Americans must accept that black Americans experience encounters with the police in a way that drastically differs from white experience." ${ }^{93}$ Similarly (though I am not equating the two contexts), board members must accept that servicemembers experience mental health conditions, that mental health conditions affect behavior, and that when a mental health condition mitigates what is otherwise misconduct, the servicemember deserves an upgrade in recognition of his or her service. Board members must open their minds to understanding that behavior that looks like misconduct is actually behavior consistent with coping with a mental health condition, and they must be open to alternative narratives that recognize honorable service in the face of a mental health condition. Likewise, board members must be open to acknowledging that their own experiences without (or even with) a mental health condition may drastically differ from a veteran-applicant's experience.

While there may be a number of ways to improve liberal consideration's implementation, one way is for board members to recognize and reject existing negative neural pathways that are inconsistent with liberal consideration. This article suggests that categories and embedded 
knowledge structures contribute to the boards' regular pattern of denying relief, consistent with the boards' historical approach but inconsistent with the principles of liberal consideration. Building awareness of the invisible reasons for rejecting the liberal consideration story can lead board members to consider each veteran's request in the specific context of liberal consideration, use the principles of liberal consideration to justify relief, and create new positive neural pathways to recognize and honor those who have served while enduring a mental health condition.

Liberal consideration as a policy is consistent with a three-part process for "persuad[ing] people to adopt a view that conflicts with what they already know." 94 Here, what board members already know-or think they know-is that misconduct is willful and therefore deserves an otherthan-honorable discharge. To disrupt that thinking, the first step is to provide relevant evidence. ${ }^{95}$ Second, that relevant evidence should be "inconsistent with pre-existing knowledge structures." ${ }^{96}$ And third, the relevant evidence should be presented "in circumstances in which the audience can attend to the evidence." ${ }^{97}$

The DoD Policy Memo takes all three steps. First, it acknowledges the research connecting mental health conditions and behavior; that is the relevant evidence. Second, the evidence of this connection is inconsistent with historic thinking that all misconduct was willful. Third, the Policy Memo lays out specific application of liberal consideration to facts presented by veteran-applicants in their discharge upgrade requests. The Memo gives the audience-board members-a mechanism for attending to and assessing the evidence. For example, when an application presents a mental health condition as a mitigating factor, liberal consideration is triggered.

Even when presented with this relevant and inconsistent evidence, there is no guarantee of change (as is obvious from liberal consideration's lackluster results thus far), but the challenge itself should not stop board members from seeking a path to changing their embedded knowledge structures. ${ }^{98}$ For example, with full awareness of how response-reinforcement has thwarted liberal consideration, the boards could intentionally create a new category based on the principles of liberal consideration. Instead of equating all misconduct with willful behavior, board members could explicitly discuss how mental health mitigates or does

94 Berger, supra note 43, at 299. 
not mitigate behavior in each decision that is based on an application that asserts a mental health condition. Grappling with the question of mitigation (rather than automatically rejecting it) could help board members' brains engage in new thinking and create new pathways. A new category or new categories could improve implementation of liberal consideration, even if only to some degree, simply by creating an awareness and potential openness to the new story. Of course, as warfare changes and as research continues to explore and explain the relationship between behavior and mental health conditions, there may be a future need for another break from relatively new embedded knowledge structures or categories.

In the unique realm of discharge review boards, most applicants for relief are pro se, and decisions are often made on the record alone. Given the typical lack of advocacy on behalf of the veterans seeking relief, board members themselves should take on the role of rejecting embedded knowledge structures. Liberal consideration creates the opportunity for board members to do just that: to liberally consider the facts and to imagine an individual veteran's request for relief within the context of PTSD or other mental health condition with the full "complexity, diversity, and fluidity of human experience." ${ }^{99}$ In the liberal consideration story, the DoD Policy Memo is the storyteller and board members are the audience. But board members are also more than the audience; they are obligated to do more than passively listen to the story. Due to the pro se status of most applicants and the policy mandate for liberal consideration in cases involving mental health conditions, board members are obligated to engage with the story, to facilitate its telling. Armed with some possible explanation for resisting the liberal consideration story thus far, board members now have an opportunity to embrace liberal consideration as an integral part of their decisionmaking. With this better understanding of the invisible reasons for denying upgrade requests, the liberal consideration story stands a better chance of being heard and used to grant upgrades to veterans with invisible wounds. 